\title{
The mucormycosis surge in COVID-19 pandemic: an analysis of associated risk factors and review of literature of reported cases
}

\author{
Chandrashekhar Mahato ${ }^{1 *}$, Navneet Magon $^{2}$, Shail Prasad $^{2}$, Amit Kumar Tyagi $^{3}$
}

\begin{abstract}
${ }^{1}$ Department of Health, Central Health Services, Central Institute of Psychiatry, Ranchi, India
${ }^{2}$ Division of Reconstructive \& Cosmetic Gynecology, All India Institute of Medical Sciences Rishikesh, Uttarakhand, India

${ }^{3}$ Associate Professor, Department of Otorhinolaryngology, Head of Mucormycosis Team, All India Institute of Medical Sciences, Rishikesh, Uttarakhand, India
\end{abstract}

Received: 04 January 2022

Accepted: 04 February 2022

\section{*Correspondence:}

Dr. Chandrashekhar Mahato,

E-mail: mahato.chandrashekhar@gmail.com

Copyright: ( ) the author(s), publisher and licensee Medip Academy. This is an open-access article distributed under the terms of the Creative Commons Attribution Non-Commercial License, which permits unrestricted non-commercial use, distribution, and reproduction in any medium, provided the original work is properly cited.

\begin{abstract}
COVID-19 patients are particularly susceptible to secondary infections, both bacterial and fungal, most likely due to immunological dysregulation. Secondary systemic mucormycosis was identified to be the significant cause of this epidemic among fungal infections. Post-COVID-19 complications are being reported all around the world, creating major pressure on healthcare services and the lives of the patients. PRISMA guidelines were used to conduct a literature review for articles published on COVID-19 associated Mucormycosis (CAM) between January 1, 2020, to May 18, 2021. The inclusion criteria were based on peer-reviewed studies in English covering cases with COVIDassociated mucormycosis (CAM). Articles describing fungal coinfections that were not mucormycosis cases, nonCOVID-19 cases, and studies with a lack of clarity were excluded from the review. The review includes 31 articles comprising of 21 Case Reports and 10 Case Series. Out of 104 cases, 76\% were from India, 77.9\% were males. Predisposing variables such as diabetes $(71.15 \%)$, hypertension $(37.5 \%)$, and ketoacidosis $(10.6 \%)$ were found to be substantial contributors to the aggressive growth of opportunistic fungal infections such as mucormycosis. Rhinoorbital mucormycosis $(n=47)$, followed by Rhino-orbital-cerebral mucormycosis $(n=32)$, and Pulmonary mucormycosis $(n=10)$ were commonly reported in the case studies and literature reviews which presented either following COVID-19 infection or a few weeks after active COVID-19 infection. Significant mortality (36.9\%) was reported among patients. As per our observations, CAM could be a serious consequence of severe COVID-19, especially in people with uncontrolled diabetes.
\end{abstract}

Keywords: COVID-19, Mucormycosis, Diabetes mellitus, CAM, SARS Co-V2

\section{INTRODUCTION}

The novel SARS-CoV2 virus causes COVID -19 infection has been attributed to a wide range of disease patterns, from a mild cough to life-threatening pneumonia. ${ }^{1}$ COVID-19 is linked to a high rate of secondary infections, both bacterial and fungal, most likely as a result of immunological dysregulation. Furthermore, the frequent use of steroids, broad-spectrum antibiotics, and monoclonal antibodies against COVID19 may result in the formation or aggravation of a preexisting fungal infection. ${ }^{2}$

Mucormycosis is a rare, opportunistic angio-invasive illness caused by a saprophytic Mucorales fungus. Fungal spores are easily aerosolized and can enter the human body by inhalation, local inoculation (such as a skin lesion), or gastrointestinal absorption. The establishment 
of the fungi and progression of mucormycosis requires specific crucial phases regardless of the point of entrance. ${ }^{3}$ This includes spore inoculation on host tissue; evading phagocytosis and germinating into angioinvasive hyphae. The Mucorales use certain host circumstances (e.g., hyperglycemia, ketoacidosis, iron overload, etc.) to boost their development and pathogenicity. In mice models of mucormycosis, increased iron concentrations promote fungal growth by limiting phagocyte function and lowering IFN-secretion. ${ }^{4}$ The actual prevalence of mucormycosis in India is unknown due to a lack of population-based studies. Mucormycosis is estimated to be 70 times more prevalent in India than it is in the rest of the world. ${ }^{5}$

Increased awareness, advancements in diagnostic techniques, and the prevalence of predisposing variables are all attributing to an upward trend. Mucormycosis is most common in immunocompromised patients, such as those with haematological malignancies, transplant recipients, in people with uncontrolled diabetes mellitus, and, even more rarely, immunocompetent patients. ${ }^{6}$ With the extensive use of broad-spectrum antibiotics and steroids, $8 \%$ of coronavirus-positive or recovered patients had secondary bacterial or fungal infections during hospitalization, according to a recent study. ${ }^{7}$ COVID-19 is a life-threatening infectious disease in which patients has an overexpression of inflammatory cytokines and impaired cell-mediated immunity, as evidenced by a decrease in the number of cluster of differentiation 4 and 8 positive $\mathrm{T}$-helper (CD4+ $\mathrm{T}$ and $\mathrm{CD} 8+\mathrm{T}$ ) cells, indicating susceptibility to fungal co-infection. India has a high prevalence rate of type 2 diabetes mellitus $(8.9 \%$ of adults, 77 million patients), which is a well-known risk factor. ${ }^{8}$

Without early diagnosis and treatment, the illness may proceed quickly, with fatality rates of $50-80 \%$ reported from intra-orbital and cerebral complications. Care is frequently ineffective, resulting in infection spread and fatality, despite the prompt diagnosis, treatment of underlying illnesses, and intensive medical and surgical intervention. $^{7}$

\section{METHODS}

For systematic reviews, the search method and analysis were carried out following the Preferred Reporting Items for Systematic Reviews and Meta-analyses (PRISMA) guidelines.9 Full-length publications were appraised for eligibility after the titles and abstracts of the retrieved papers were examined. No unpublished information was obtained.

\section{Search strategy}

Two investigators (S.P. and C.M.) have independently performed a systematic search of the literature across Google Scholar, PubMed, ScienceDirect, and Web of Science for 'COVID-19', 'SARS-CoV-2',
'Mucormycosis', 'Ophthalmic manifestations', 'Diabetes', 'Immunosuppressants', 'COVID associated mucormycosis' and 'intravenous liposomal Amphotericin-B'.

\section{Inclusion and exclusion criteria}

\section{Inclusion criteria}

Considering articles for review in the English language. Covering COVID Associated Mucormycosis (CAM) cases published between January, 2020, to May, 2021. Patients with confirmed COVID-19 cases (either active or recovered) were involved in the study. Case reports, case series, and cross-sectional studies associated with mucormycosis were involved in the study.

\section{Exclusion criteria}

Articles with other fungal infections that were not mucormycosis were excluded from the study. Patients without confirmed COVID-19 diagnosis were excluded from the study.

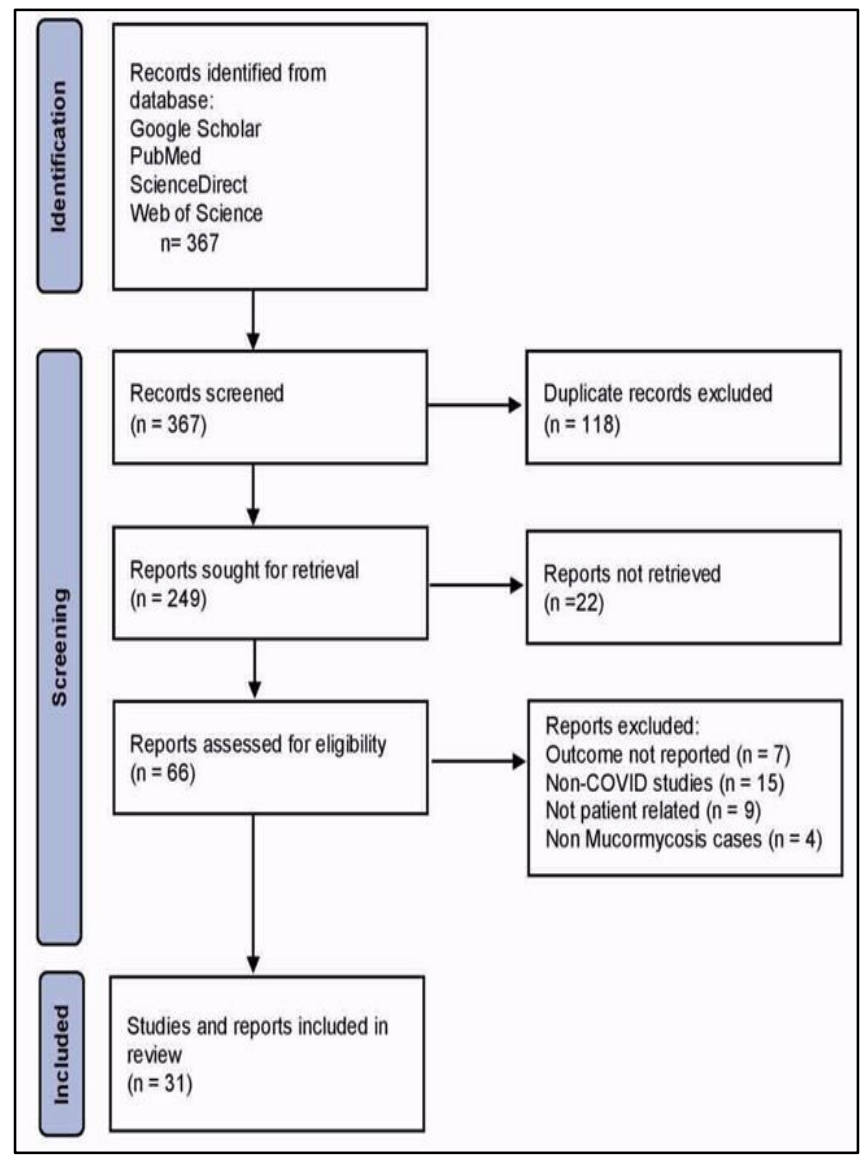

Figure 1: Flow diagram of the study selection process.

\section{Data extraction}

Two investigators (S.P. and C.M.) independently performed data collection. The literature review included 
31 records, in which 14 articles from India and 17 articles worldwide were included. The review consisted of 21 case reports and 10 case series. Selected studies were reviewed and data extracted in terms of country of study, patients symptomatology, history of COVID-19 (active or recovered), associated predisposing comorbidities, presence of diabetes mellitus, diabetic ketoacidosis, corticosteroid use, use of Remdesivir, use of intravenous liposomal Amphotericin-B and other antifungal agents, surgical intervention, type of mucormycosis, investigation (laboratory blood test, radiological test, CT scan, MRI, histological finding, fungal culture report, etc.), treatment outcome in term of alive, dead or lost in follow-up.

\section{Statistics}

The socio-demographic data along with other variables were represented in percentage. The age of patients in the case series was shown as mean age in years.

\section{RESULTS}

The literature review included 31 records out of 367 articles that were searched for this paper using PRISMA guidelines as seen in the flow diagram of Figure 1.

Table 1 depicts the characteristics of CAM patients. 79 and 11 proven mucormycosis cases were reported from India and the United States of America respectively, out of the 104 confirmed CAM cases. Until May 18, 2021, 10 instances have also been recorded from Iran, 02 from Brazil, 01 from Italy, and 01 from Mexico. The median age was 54 years with the range being 24 years to 86 years. 81/104 (77.9\%) were male and 23/104 (22.1\%) were female. All reported cases have been diagnosed as a case of COVID-19 disease by RTPCR or other confirmatory tests. In our review, the most common medical comorbid illnesses were diabetes mellitus 74/104 $(71.15 \%), 39 / 104(37.5 \%)$ cases hypertension, $11 / 104$ $(10.6 \%)$ cases had diabetic ketoacidosis, followed by 9/104 (6.7\%) had renal disorders, 6/104 (5.77\%) had respiratory disorders, and 5/104 (4.8\%) had cardiovascular disorders.

Table 2 gives a summary of the case reports and series and their interpretation. The most common presentation was rhino-orbital mucormycosis 45/104 (43.27\%), followed by $32 / 104(30.77 \%)$ had Rhino-orbital-cerebral mucormycosis, 10/104 (9.62\%) presented with pulmonary mucormycosis.

In our review, out of 104 CAM cases, 36/104 (34.62\%) of the patients were treated with injection Remdesivir, 95/104 (91.8\%) patients received intravenous corticosteroids during COVID-19 treatment, while 99/104 (95.19\%) cases received intravenous liposomal Amphotericin-B for treatment of mucormycosis. A combination of antifungal agents was used in 34/104 $(32.7 \%)$ cases, the most common combination used was
Posaconazole 21/104 (20.2\%) along with intravenous liposomal Amphotericin-B. Combined medical and surgical management was performed in 85/104 (81.73\%) of the cases. In our study overall mortality was reported to be $36.9 \%$.

Table 1: Characteristics of the 104 patients with COVID associated mucormycosis (CAM).

\begin{tabular}{|c|c|c|}
\hline Variable $(n=104)$ & & $\mathbf{N}(\%)$ \\
\hline \multirow{6}{*}{$\begin{array}{l}\text { Country where } \\
\text { the cases were } \\
\text { reported }\end{array}$} & India & $79(76)$ \\
\hline & $\begin{array}{l}\text { United States of } \\
\text { America }\end{array}$ & $11(10.6)$ \\
\hline & Iran & $10(9.6)$ \\
\hline & Brazil & $2(1.9)$ \\
\hline & Italy & $1(0.95)$ \\
\hline & Mexico & $1(0.95)$ \\
\hline \multirow{2}{*}{ Sex } & Male & $81(77.9)$ \\
\hline & Female & $23(22.1)$ \\
\hline \multirow{6}{*}{$\begin{array}{l}\text { Underlying } \\
\text { factors }\end{array}$} & Diabetes & $74(71.15)$ \\
\hline & Hypertension & $39(37.5)$ \\
\hline & $\begin{array}{l}\text { Diabetic } \\
\text { Ketoacidosis }\end{array}$ & $11(10.6)$ \\
\hline & Renal Disorders & $9(8.65)$ \\
\hline & $\begin{array}{l}\text { Respiratory } \\
\text { Disorders }\end{array}$ & $6(5.77)$ \\
\hline & $\begin{array}{l}\text { Cardiovascular } \\
\text { Disorders }\end{array}$ & $5(4.8)$ \\
\hline \multirow{5}{*}{ Management } & Remdesivir & $36(34.62)$ \\
\hline & Corticosteroids & $95(71.8)$ \\
\hline & $\begin{array}{l}\text { Liposomal } \\
\text { Amphoterin-B }\end{array}$ & $99(95.19)$ \\
\hline & $\begin{array}{l}\text { Other Antifungal } \\
\text { agents }\end{array}$ & $34(32.7)$ \\
\hline & $\begin{array}{l}\text { Combined } \\
\text { medical and } \\
\text { surgical } \\
\text { management }\end{array}$ & $85(81.73)$ \\
\hline \multirow{3}{*}{ Outcome } & Alive & $63(61.1)$ \\
\hline & Death & $38(36.9)$ \\
\hline & Not known & $3(2.9)$ \\
\hline
\end{tabular}

\section{DISCUSSION}

Patients who require critical care due to COVID-19 pneumonia have risk factors and underlying conditions that make them susceptible to invasive fungal infections. Uncontrolled Diabetes mellitus, particularly diabetic ketoacidosis, is a prevalent predisposing condition. ${ }^{10}$

Out of the 104 confirmed mucormycosis cases, 79 were reported from India, 11 cases were from the United States of America, 10 cases were reported from Iran and 2 from Brazil, 1 case from Italy, and 1 was reported from Mexico till 18 May 2021. In our study maximum cases were reported from India (76\%). 
Table 2: Summary of the review of 31 literature (or 104 cases) in COVID Associated Mucormycosis.

\begin{tabular}{|c|c|c|c|c|c|c|c|c|c|c|c|c|}
\hline Authors & $\begin{array}{l}\text { Coun } \\
\text { try }\end{array}$ & $\begin{array}{l}\text { Age } \\
\text { in } \\
\text { years }\end{array}$ & $\begin{array}{l}\text { Se } \\
\mathbf{x}\end{array}$ & $\begin{array}{l}\text { Study } \\
\text { Design }\end{array}$ & $\begin{array}{l}\text { Comorbid } \\
\text { Illness }\end{array}$ & $\begin{array}{l}\text { Clinical } \\
\text { Presentation }\end{array}$ & $\begin{array}{l}\text { Treatment for } \\
\text { COVID-19 }\end{array}$ & $\begin{array}{l}\text { Specific } \\
\text { treatments }\end{array}$ & $\begin{array}{l}\text { Investigation } \\
\mathrm{S}\end{array}$ & $\begin{array}{l}\text { COVID } \\
-19 \\
\text { testing }\end{array}$ & $\begin{array}{l}\text { Type of } \\
\text { involvemen } \\
t \text { in CAM }\end{array}$ & $\begin{array}{l}\text { Outco } \\
\text { me }\end{array}$ \\
\hline 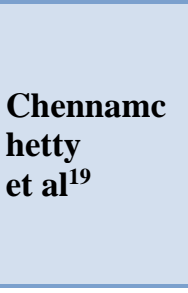 & India & 72 & $\begin{array}{l}\text { M } \\
\text { ale }\end{array}$ & $\begin{array}{l}\text { Case } \\
\text { report }\end{array}$ & $\begin{array}{l}\text { Hypertension, } \\
\text { Steroid- } \\
\text { induced } \\
\text { Diabetes } \\
\text { Mellitus, } \\
\text { Hypothyroidis } \\
\text { m }\end{array}$ & $\begin{array}{l}\text { COVID-19 } \\
\text { pneumonia, } \\
\text { Severe ARDS, } \\
\text { hemoptysis }\end{array}$ & $\begin{array}{l}\text { Inj. Remdesivir, } \\
\text { methylprednisol } \\
\text { one, } \\
\text { Convalescent } \\
\text { plasma, } \\
\text { Antibiotics }\end{array}$ & $\begin{array}{l}\text { Liposomal } \\
\text { Amphotericin- } \\
\text { B, Tab. } \\
\text { Posaconazole } \\
\text { at discharge }\end{array}$ & $\begin{array}{l}\text { PET CT scan, } \\
\text { CT guided } \\
\text { biopsy of a } \\
\text { nodule in } \\
\text { right upper } \\
\text { lobe, blood } \\
\text { culture }\end{array}$ & $\begin{array}{l}\text { COVID } \\
+\end{array}$ & Pulmonary & Alive \\
\hline $\begin{array}{l}\text { Dronamraj } \\
\text { u et } \text { al }^{20}\end{array}$ & India & 50 & $\begin{array}{l}\text { M } \\
\text { ale }\end{array}$ & $\begin{array}{l}\text { Case } \\
\text { report }\end{array}$ & $\begin{array}{l}\text { Recent history } \\
\text { of COVID-19 } \\
\text { Pneumonia }\end{array}$ & $\begin{array}{l}\text { Headache, } \\
\text { Diminished } \\
\text { vision in the } \\
\text { right eye, } \\
\text { Swelling of the } \\
\text { right eyelid, } \\
\text { Nasal blockage, } \\
\text { h/o fever, } \\
\text { tenderness over } \\
\text { sinuses }\end{array}$ & $\begin{array}{l}\text { Supportive } \\
\text { antibiotics }\end{array}$ & $\begin{array}{l}\text { Liposomal } \\
\text { Amphotericin } \\
\text { B }\end{array}$ & $\begin{array}{l}\text { MRI brain, } \\
\text { CT scan } \\
\text { brain, Nasal } \\
\text { swab culture }\end{array}$ & $\begin{array}{l}\text { COVID } \\
-19 \\
\text { RTPCR } \\
+\end{array}$ & $\begin{array}{l}\text { Rhinocerebr } \\
\text { al }\end{array}$ & Death \\
\hline $\begin{array}{l}\text { Garg et } \\
\text { al }^{21}\end{array}$ & India & 55 & $\begin{array}{l}\text { M } \\
\text { ale }\end{array}$ & $\begin{array}{l}\text { Case } \\
\text { report } \\
\text { and } \\
\text { system } \\
\text { atic } \\
\text { review }\end{array}$ & $\begin{array}{l}\text { Diabetes } \\
\text { mellitus, } \\
\text { Hypertension, } \\
\text { Ischemic } \\
\text { cardiomyopath } \\
\text { y, End-stage } \\
\text { renal disease, } \\
\text { h/o dialysis }\end{array}$ & $\begin{array}{l}\text { Fever, Dry } \\
\text { cough, } \\
\text { Progressive } \\
\text { breathlessness }\end{array}$ & $\begin{array}{l}\text { Inj. Meropenem, } \\
\text { Inj. Remdesivir } \\
\text { Dexamethasone, }\end{array}$ & $\begin{array}{l}\text { Liposomal } \\
\text { Amphotericin } \\
-B\end{array}$ & $\begin{array}{l}\text { Chest X-ray, } \\
\text { CT CHEST, } \\
\text { SDA culture } \\
\text { of pleural } \\
\text { effusion, LCB } \\
\text { mount, } \\
\text { MALDI TDF, } \\
\text { S. } \\
\text { galactomanna } \\
\text { n }\end{array}$ & $\begin{array}{l}\text { COVID } \\
-19 \\
\text { RTPCR } \\
+\end{array}$ & Pulmonary & Alive \\
\hline
\end{tabular}

Continued. 


\begin{tabular}{|c|c|c|c|c|c|c|c|c|c|c|c|c|}
\hline Authors & $\begin{array}{l}\text { Coun } \\
\text { try }\end{array}$ & $\begin{array}{l}\text { Age } \\
\text { in } \\
\text { years }\end{array}$ & $\begin{array}{l}\mathrm{Se} \\
\mathrm{x}\end{array}$ & $\begin{array}{l}\text { Study } \\
\text { Design }\end{array}$ & $\begin{array}{l}\text { Comorbid } \\
\text { Illness }\end{array}$ & $\begin{array}{l}\text { Clinical } \\
\text { Presentation }\end{array}$ & $\begin{array}{l}\text { Treatment for } \\
\text { COVID-19 }\end{array}$ & $\begin{array}{l}\text { Specific } \\
\text { treatments }\end{array}$ & $\begin{array}{l}\text { Investigation } \\
\mathrm{S}\end{array}$ & $\begin{array}{l}\text { COVID } \\
-19 \\
\text { testing }\end{array}$ & $\begin{array}{l}\text { Type of } \\
\text { involvemen } \\
t \text { in CAM }\end{array}$ & $\begin{array}{l}\text { Outco } \\
\text { me }\end{array}$ \\
\hline $\begin{array}{l}\text { Honavar et } \\
\text { al }^{22}\end{array}$ & India & $\begin{array}{l}60.5 \pm \\
12 \\
(\text { mean } \\
) \\
n=3\end{array}$ & $\begin{array}{l}M \\
\text { ale } \\
-3\end{array}$ & $\begin{array}{l}\text { Retros } \\
\text { pective } \\
\text { interve } \\
\text { ntional } \\
\text { study }\end{array}$ & $\begin{array}{l}\text { Diabetes } \\
\text { mellitus } \\
\text { (common), } \\
\text { Hypertension, } \\
\text { Coronary } \\
\text { artery disease }\end{array}$ & $\begin{array}{l}\text { Ophthalmoplegi } \\
\text { a, Ptosis, } \\
\text { Chemosis }\end{array}$ & $\begin{array}{l}\text { Methylprednisol } \\
\text { one, } \\
\text { Prednisolone, } \\
\text { Dexamethasone }\end{array}$ & $\begin{array}{l}\text { FESS, } \\
\text { Amphotericin- } \\
\text { B, Inj. } \\
\text { Posaconazole }\end{array}$ & $\begin{array}{l}\text { Culture for } \\
\text { Mucor } \\
(66.67 \%), \\
\text { Histopatholog } \\
\text { y }(66.67 \%),\end{array}$ & $\begin{array}{l}\text { COVID } \\
+\end{array}$ & $\begin{array}{l}\text { Rhino- } \\
\text { orbital-3 }\end{array}$ & $\begin{array}{l}\text { Alive- } \\
3\end{array}$ \\
\hline $\begin{array}{l}\text { Maini et } \\
\text { al }^{23}\end{array}$ & India & 38 & $\begin{array}{l}\text { M } \\
\text { ale }\end{array}$ & $\begin{array}{l}\text { Case } \\
\text { Report }\end{array}$ & $\begin{array}{l}\text { No h/o } \\
\text { Diabetes, or } \\
\text { any } \\
\text { debilitating } \\
\text { disorder } \\
\text { before } \\
\text { treatment. }\end{array}$ & $\begin{array}{l}\text { Fever, Cough, } \\
\text { Breathlessness, } \\
\text { Malaise, } \\
\text { Proptosis, } \\
\text { Chemosis }\end{array}$ & $\begin{array}{l}\text { Inj. Remdesivir, } \\
\text { Methylprednisol } \\
\text { one, } \\
\text { Dexamethasone }\end{array}$ & $\begin{array}{l}\text { Inj. } \\
\text { Pipracillin+ } \\
\text { Tazobactum, } \\
\text { Metronidazole } \\
\text {, Fluconazole, } \\
\text { Inj. } \\
\text { Amphotericin- } \\
\text { B, } \\
\text { Tobramycin, } \\
\text { Surgical } \\
\text { debridement } \\
\text { of necrotic } \\
\text { tissue }\end{array}$ & $\begin{array}{l}\text { Complete } \\
\text { Blood Count, } \\
\text { Blood Sugar } \\
\text { estimation, } \\
\text { Histopatholog } \\
\text { y, IL-6, CRP, } \\
\text { D-dimer, } \\
\text { MRI brain } \\
\text { and orbit }\end{array}$ & $\begin{array}{l}\text { COVID } \\
-19 \\
\text { RTPCR } \\
+\end{array}$ & $\begin{array}{l}\text { Rhino- } \\
\text { orbital- } \\
\text { cerebral }\end{array}$ & Alive \\
\hline $\begin{array}{l}\text { Mehta et } \\
\text { al }^{1}\end{array}$ & India & 60 & $\begin{array}{l}\text { M } \\
\text { ale }\end{array}$ & $\begin{array}{l}\text { Case } \\
\text { Report }\end{array}$ & $\begin{array}{l}\text { Diabetes } \\
\text { mellitus, } \\
\text { Lung disease, }\end{array}$ & $\begin{array}{l}\text { Severe } \\
\text { breathlessness, } \\
\text { Pyrexia, } \\
\text { Tachypnea, } \\
\text { Generalized } \\
\text { malaise, Non- } \\
\text { healing ulcer on } \\
\text { the right foot, } \\
\text { Bilateral lid } \\
\text { edema }\end{array}$ & $\begin{array}{l}\text { Inj. Meropenem, } \\
\text { oral } \\
\text { Oseltamivir, } \\
\text { methylprednisol } \\
\text { one, } \\
\text { Dexamethasone, } \\
\text { Inj. insulin, Inj. } \\
\text { Tocilizumab }\end{array}$ & $\begin{array}{l}\text { Inj. } \\
\text { Amphotericin- } \\
B, \text { inj. } \\
\text { Vancomycin }\end{array}$ & $\begin{array}{l}\text { Chest CT } \\
\text { scan, MRI } \\
\text { brain, nasal } \\
\text { and paranasal } \\
\text { sinuses, SDA } \\
\text { culture for } \\
\text { mucormycosi } \\
\text { s, }\end{array}$ & $\begin{array}{l}\text { COVID } \\
19 \\
\text { RTPCR } \\
+\end{array}$ & $\begin{array}{l}\text { Rhino- } \\
\text { orbital }\end{array}$ & Death \\
\hline $\begin{array}{l}\text { Mishra et } \\
\text { al }^{24}\end{array}$ & India & $\begin{array}{l}59 \\
\text { (mean } \\
) \\
\pm 14.6 \\
3 \\
\mathrm{n}=10\end{array}$ & $\begin{array}{l}\text { M } \\
\text { ale } \\
-9 \\
\text { Fe } \\
\text { ma } \\
\text { le- } \\
1\end{array}$ & $\begin{array}{l}\text { Retros } \\
\text { pective } \\
\text { Analys } \\
\text { is }\end{array}$ & $\begin{array}{l}\text { Diabetes } \\
\text { mellitus-8, } \\
\text { Hypertension- } \\
\text { 3, Ischemic } \\
\text { heart disease, } \\
\text { Chronic } \\
\text { kidney }\end{array}$ & $\begin{array}{l}\text { Right eye pain, } \\
\text { Chemosis, Loss } \\
\text { of vision, } \\
\text { Epistaxis, } \\
\text { Bleeding gums }\end{array}$ & $\begin{array}{l}\text { Steroids, Inj. } \\
\text { Remdesivir, Inj. } \\
\text { Tocilizumab }\end{array}$ & $\begin{array}{l}\text { FESS, Orbital } \\
\text { exenteration, } \\
\text { Local } \\
\text { debridement, } \\
\text { Inj. } \\
\text { Amphotericin } \\
\text { B, Inj. }\end{array}$ & $\begin{array}{l}\text { Histopatholog } \\
\text { ical } \\
\text { examination, } \\
\text { fungal smear, } \\
\text { CT PNS, CT } \\
\text { Brain }\end{array}$ & $\begin{array}{l}\text { COVID } \\
-19+\end{array}$ & $\begin{array}{l}\text { Rhino- } \\
\text { orbital- } \\
\text { cerebral -10 }\end{array}$ & $\begin{array}{l}\text { Alive- } \\
5 \\
\text { Death- } \\
4 \\
\text { Lost in } \\
\text { the } \\
\text { follow- }\end{array}$ \\
\hline
\end{tabular}




\begin{tabular}{|c|c|c|c|c|c|c|c|c|c|c|c|c|}
\hline Authors & $\begin{array}{l}\text { Coun } \\
\text { try }\end{array}$ & $\begin{array}{l}\text { Age } \\
\text { in } \\
\text { years }\end{array}$ & $\begin{array}{l}\text { Se } \\
\mathbf{x}\end{array}$ & $\begin{array}{l}\text { Study } \\
\text { Design }\end{array}$ & $\begin{array}{l}\text { Comorbid } \\
\text { Illness }\end{array}$ & $\begin{array}{l}\text { Clinical } \\
\text { Presentation }\end{array}$ & $\begin{array}{l}\text { Treatment for } \\
\text { COVID-19 }\end{array}$ & $\begin{array}{l}\text { Specific } \\
\text { treatments }\end{array}$ & $\begin{array}{l}\text { Investigation } \\
\mathrm{s}\end{array}$ & $\begin{array}{l}\text { COVID } \\
-19 \\
\text { testing }\end{array}$ & $\begin{array}{l}\text { Type of } \\
\text { involvemen } \\
t \text { in CAM }\end{array}$ & $\begin{array}{l}\text { Outco } \\
\text { me }\end{array}$ \\
\hline & & & & & $\begin{array}{l}\text { disease- 2, } \\
\text { Chronic liver } \\
\text { disease, } \\
\text { Hypothyroidis } \\
\text { m- 2, } \\
\text { No } \\
\text { comorbidity-1 }\end{array}$ & & & $\begin{array}{l}\text { Posaconazole, } \\
\text { Endoscopic } \\
\text { maxillectomy, } \\
\text { ethmoidectom } \\
\mathrm{y},\end{array}$ & & & & up- 1 \\
\hline $\begin{array}{l}\text { Moorthy et } \\
\text { al }^{8}\end{array}$ & India & $\begin{array}{l}54.6 \\
(\text { mean } \\
) \\
\pm 10.4 \\
\mathrm{n}=18\end{array}$ & $\begin{array}{l}\text { M } \\
\text { ale } \\
- \\
15 \\
\mathrm{Fe} \\
\mathrm{ma} \\
\text { le- } \\
3\end{array}$ & $\begin{array}{l}\text { Retros } \\
\text { pective } \\
\text { multice } \\
\text { ntre } \\
\text { observ } \\
\text { ational } \\
\text { study }\end{array}$ & $\begin{array}{l}\text { Uncontrolled } \\
\text { diabetes- } 16 \\
\text { Non-diabetic- } \\
2 \text {, Steroid- } 16\end{array}$ & $\begin{array}{l}\text { Maxillary } \\
\text { sinusitis, Loss } \\
\text { of vision }\end{array}$ & $\begin{array}{l}\text { COVID-19 } \\
\text { symptomatic } \\
\text { management }\end{array}$ & $\begin{array}{l}\text { Inj. } \\
\text { Amphotericin- } \\
\text { B, Orbital } \\
\text { exenteration- } \\
7 \text {, FESS- 17, } \\
\text { Maxillectomy- } \\
11\end{array}$ & $\begin{array}{l}\text { Routine blood } \\
\text { examination, } \\
\text { X-ray Chest, } \\
\text { CT scan, } \\
\text { MRI, fungal } \\
\text { culture }\end{array}$ & $\begin{array}{l}\text { COVID } \\
-19 \\
\text { RTPCR } \\
+ \\
\text { Previou } \\
\text { s h/o } \\
\text { infectio } \\
\text { n- 15, } \\
\text { on } \\
\text { admissi } \\
\text { on- 3 }\end{array}$ & $\begin{array}{l}\text { Rhino- } \\
\text { orbital- 9, } \\
\text { Rhino- } \\
\text { orbital- } \\
\text { cerebral- } 9\end{array}$ & $\begin{array}{l}\text { Alive- } \\
11, \\
\text { Death- } \\
6, \\
\text { Unkno } \\
\text { wn- } 1\end{array}$ \\
\hline $\begin{array}{l}\text { Revannava } \\
r \text { et } \text { al }^{25}\end{array}$ & India & $\begin{array}{l}\text { Middl } \\
\text { e- } \\
\text { aged }\end{array}$ & $\begin{array}{l}\mathrm{Fe} \\
\mathrm{ma} \\
\mathrm{le}\end{array}$ & $\begin{array}{l}\text { Case } \\
\text { report }\end{array}$ & $\begin{array}{l}\text { Diabetes } \\
\text { mellitus }\end{array}$ & $\begin{array}{l}\text { Ptosis, Facial } \\
\text { pain, } \\
\text { Ophthalmoplegi } \\
\text { a }\end{array}$ & $\begin{array}{l}\text { Aspirin, Inj. } \\
\text { Amphotericin- } \\
\text { B, }\end{array}$ & $\begin{array}{l}\text { FESS, Insulin } \\
\text { therapy }\end{array}$ & $\begin{array}{l}\text { CBC, LFT, } \\
\text { KFT, S. } \\
\text { Electrolytes, } \\
\text { CRP, D- } \\
\text { dimer, S. } \\
\text { ferritin, S. } \\
\text { procalcitonin, } \\
\text { CT Paranasal } \\
\text { sinus, MRI } \\
\text { brain, } \\
\text { Histopatholog } \\
\text { y }\end{array}$ & $\begin{array}{l}\text { RTPCR } \\
+\end{array}$ & $\begin{array}{l}\text { Rhino- } \\
\text { orbital }\end{array}$ & Alive \\
\hline $\begin{array}{l}\text { Saldanha } \\
\text { et } \mathbf{a l}^{26}\end{array}$ & India & 32 & $\begin{array}{l}\mathrm{Fe} \\
\mathrm{ma} \\
\mathrm{le}\end{array}$ & $\begin{array}{l}\text { Case } \\
\text { report }\end{array}$ & $\begin{array}{l}\text { Uncontrolled } \\
\text { diabetes } \\
\text { mellitus }\end{array}$ & $\begin{array}{l}\text { Left eye Ptosis, } \\
\text { Left facial pain }\end{array}$ & $\begin{array}{l}\text { Supportive } \\
\text { antibiotics }\end{array}$ & $\begin{array}{l}\text { Amphotericin } \\
\text { B, Endonasal } \\
\text { Surgery }\end{array}$ & $\begin{array}{l}\text { Nasal } \\
\text { endoscopy, } \\
\text { CT scan nose, } \\
\text { and paranasal } \\
\text { sinus, MRI, } \\
\text { Nasal swab }\end{array}$ & $\begin{array}{l}\text { CBNA } \\
\text { AT for } \\
\text { covid- } \\
19+, \\
\text { COVID } \\
19\end{array}$ & $\begin{array}{l}\text { Rhino- } \\
\text { orbital } \\
\text { cerebral }\end{array}$ & Alive \\
\hline
\end{tabular}




\begin{tabular}{|c|c|c|c|c|c|c|c|c|c|c|c|c|}
\hline Authors & $\begin{array}{l}\text { Coun } \\
\text { try }\end{array}$ & $\begin{array}{l}\text { Age } \\
\text { in } \\
\text { years }\end{array}$ & $\begin{array}{l}\text { Se } \\
\mathbf{x}\end{array}$ & $\begin{array}{l}\text { Study } \\
\text { Design }\end{array}$ & $\begin{array}{l}\text { Comorbid } \\
\text { Illness }\end{array}$ & $\begin{array}{l}\text { Clinical } \\
\text { Presentation }\end{array}$ & $\begin{array}{l}\text { Treatment for } \\
\text { COVID-19 }\end{array}$ & $\begin{array}{l}\text { Specific } \\
\text { treatments }\end{array}$ & $\begin{array}{l}\text { Investigation } \\
\mathrm{S}\end{array}$ & $\begin{array}{l}\text { COVID } \\
-19 \\
\text { testing }\end{array}$ & $\begin{array}{l}\text { Type of } \\
\text { involvemen } \\
\mathrm{t} \text { in CAM }\end{array}$ & $\begin{array}{l}\text { Outco } \\
\text { me }\end{array}$ \\
\hline & & & & & & & & & $\begin{array}{l}\text { for culture, } \\
\text { KOH wet } \\
\text { mount }\end{array}$ & & & \\
\hline $\begin{array}{l}\text { Sarkar et } \\
\text { al }^{27}\end{array}$ & India & $\begin{array}{l}45.5 \\
(\text { mean } \\
) \\
\pm 14.0 \\
4 \\
\mathrm{n}=10\end{array}$ & $\begin{array}{l}\text { M } \\
\text { ale } \\
- \\
8, \\
\mathrm{Fe} \\
\mathrm{ma} \\
\text { le- } \\
2\end{array}$ & $\begin{array}{l}\text { Case } \\
\text { Series }\end{array}$ & $\begin{array}{l}\text { Diabetic } \\
\text { ketoacidosis } \\
\text { (At } \\
\text { presentation- } \\
4, \text { DKA } \\
\text { ( During } \\
\text { hospitalization } \\
\text { )- 5, None- } 1\end{array}$ & $\begin{array}{l}\text { Viral } \\
\text { Pneumonia, } \\
\text { Severe ARDS, } \\
\text { Pansinusitis }\end{array}$ & $\begin{array}{l}\text { Dexamethasone, } \\
\text { Inj. Remdesivir- } \\
\text { 4, Ventilator } \\
\text { support- 9, } \\
\text { Monoclonal } \\
\text { antibodies, } \\
\text { Broad-spectrum } \\
\text { antibiotics }\end{array}$ & $\begin{array}{l}\text { Inj. } \\
\text { Amphotericin- } \\
\text { B, FESS, } \\
\text { Surgical } \\
\text { debridement, } \\
\text { Maxillectomy- } \\
4 \\
\text { Exenteration- } \\
1\end{array}$ & $\begin{array}{l}\text { MRI, CT } \\
\text { scan, KOH } \\
\text { wet mount, } \\
\text { Tissue } \\
\text { biopsy, } \\
\text { Fungal } \\
\text { culture }\end{array}$ & $\begin{array}{l}\text { COVID } \\
-19 \\
\text { RTPCR } \\
+\end{array}$ & $\begin{array}{l}\text { Rhino- } \\
\text { orbital- } 9 \\
\text { Rhino- } \\
\text { orbital- } \\
\text { cerebral- } 1\end{array}$ & $\begin{array}{l}\text { Alive- } \\
6 \\
\text { Death- } \\
4\end{array}$ \\
\hline $\begin{array}{l}\text { Sharma et } \\
\text { al }^{7}\end{array}$ & India & $\begin{array}{l}\text { Age- } \\
\text { N.A. } \\
n=23\end{array}$ & $\begin{array}{l}\text { M } \\
\text { ale } \\
- \\
15 \\
\mathrm{Fe} \\
\mathrm{ma} \\
\text { le- } \\
8\end{array}$ & $\begin{array}{l}\text { Prospe } \\
\text { ctive } \\
\text { observ } \\
\text { ational } \\
\text { study }\end{array}$ & $\begin{array}{l}\text { Uncontrolled } \\
\text { diabetes } \\
\text { mellitus- 12, } \\
\text { Controlled } \\
\text { diabetes- 9, } \\
\text { Hypertension- } \\
\text { 14, Renal } \\
\text { failure- } 1\end{array}$ & $\begin{array}{l}\text { Ethmoidal and } \\
\text { maxillary } \\
\text { sinusitis }\end{array}$ & $\begin{array}{l}\text { Steroids, Broad } \\
\text { spectrum } \\
\text { antibiotics }\end{array}$ & $\begin{array}{l}\text { Inj. } \\
\text { Amphotericin- } \\
\text { B, Surgical } \\
\text { debridement - } \\
21\end{array}$ & $\begin{array}{l}\text { MRI, CT } \\
\text { Scan }\end{array}$ & $\begin{array}{l}\text { COVID } \\
-19 \\
\text { RTPCR } \\
+ \\
\text { h/o } \\
\text { previou } \\
\text { s } \\
\text { infectio } \\
\text { n- } 19 \\
\text { currentl } \\
\text { y } \\
\text { infected } \\
-4\end{array}$ & $\begin{array}{l}\text { Rhino- } \\
\text { orbital- } 10 \\
\text { Rhino- } \\
\text { orbital- } \\
\text { cerebral- } 2 \\
\text { Hard } \\
\text { palate- } 9\end{array}$ & Alive \\
\hline
\end{tabular}




\begin{tabular}{|c|c|c|c|c|c|c|c|c|c|c|c|c|}
\hline Authors & $\begin{array}{l}\text { Coun } \\
\text { try }\end{array}$ & $\begin{array}{l}\text { Age } \\
\text { in } \\
\text { years }\end{array}$ & $\begin{array}{l}\text { Se } \\
\mathbf{X}\end{array}$ & $\begin{array}{l}\text { Study } \\
\text { Design }\end{array}$ & $\begin{array}{l}\text { Comorbid } \\
\text { Illness }\end{array}$ & $\begin{array}{l}\text { Clinical } \\
\text { Presentation }\end{array}$ & $\begin{array}{l}\text { Treatment for } \\
\text { COVID-19 }\end{array}$ & $\begin{array}{l}\text { Specific } \\
\text { treatments }\end{array}$ & $\begin{array}{l}\text { Investigation } \\
\mathrm{s}\end{array}$ & $\begin{array}{l}\text { COVID } \\
-19 \\
\text { testing }\end{array}$ & $\begin{array}{l}\text { Type of } \\
\text { involvemen } \\
t \text { in CAM }\end{array}$ & $\begin{array}{l}\text { Outco } \\
\text { me }\end{array}$ \\
\hline \multirow[t]{2}{*}{$\begin{array}{l}\text { Shirke et } \\
\text { al }^{28}\end{array}$} & \multirow[t]{2}{*}{ India } & 63 & $\begin{array}{l}\text { M } \\
\text { ale }\end{array}$ & $\begin{array}{l}\text { Case } \\
\text { series }\end{array}$ & $\begin{array}{l}\text { Diabetes } \\
\text { mellitus }\end{array}$ & $\begin{array}{l}\text { Maxillary pain, } \\
\text { Dental abscess, } \\
\text { Fever }\end{array}$ & $\begin{array}{l}\text { Inj. Amoxicillin, } \\
\text { Inj. Paracetamol }\end{array}$ & $\begin{array}{l}\text { Liposomal } \\
\text { Amphotericin } \\
\text { B, dental } \\
\text { extraction, } \\
\text { Surgical } \\
\text { debridement } \\
\text { of necrotic } \\
\text { tissue }\end{array}$ & $\begin{array}{l}\text { Facial CT } \\
\text { Scan, HRCT } \\
\text { chest, Culture } \\
\text { for fungus }\end{array}$ & $\begin{array}{l}\text { COVID } \\
-19 \\
\text { RTPCR } \\
+\end{array}$ & $\begin{array}{l}\text { Osteomyelit } \\
\text { is of } \\
\text { maxilla } \\
\text { secondary } \\
\text { to } \\
\text { Mucormyco } \\
\text { sis }\end{array}$ & Alive \\
\hline & & 45 & $\begin{array}{l}\mathrm{M} \\
\text { ale }\end{array}$ & $\begin{array}{l}\text { Case } \\
\text { series }\end{array}$ & $\begin{array}{l}\text { Hemolytic } \\
\text { anemia }\end{array}$ & $\begin{array}{l}\text { Right periorbital } \\
\text { swelling, Palate } \\
\text { swelling }\end{array}$ & $\begin{array}{l}\text { Inj. } \\
\text { Remdesivir, Inj. } \\
\text { Heparin }\end{array}$ & $\begin{array}{l}\text { inj. } \\
\text { Posaconazole, } \\
\text { Liposomal } \\
\text { Amphotericin } \\
\text { B, Surgical } \\
\text { debridement }\end{array}$ & $\begin{array}{l}\text { Facial CT } \\
\text { Scan, fungal } \\
\text { culture }\end{array}$ & $\begin{array}{l}\text { COVID } \\
19 \\
\text { RTPCR } \\
+\end{array}$ & $\begin{array}{l}\text { Rhino- } \\
\text { orbital }\end{array}$ & Death \\
\hline $\begin{array}{l}\text { Sebastian } \\
\text { et } \mathbf{a l}^{10}\end{array}$ & India & $\begin{array}{l}\begin{array}{l}61 \\
\text { (mean }\end{array} \\
\pm 2.16 \\
\mathrm{n}=3\end{array}$ & $\begin{array}{l}\text { M } \\
\text { ale } \\
-3\end{array}$ & $\begin{array}{l}\text { Case } \\
\text { series }\end{array}$ & $\begin{array}{l}\text { Diabetes } \\
\text { Mellitus- 3, } \\
\text { Hypertension, } \\
\text { Coronary } \\
\text { artery disease- } \\
\text { 1, Renal } \\
\text { disease- 2, } \\
\text { Peptic Ulcer- } \\
1\end{array}$ & $\begin{array}{l}\text { COVID-19 } \\
\text { pneumonia with } \\
\text { ARDS, } \\
\text { Periorbital } \\
\text { swelling, } \\
\text { Blackening of } \\
\text { the middle } \\
\text { turbinate, } \\
\text { Shock, Renal } \\
\text { Failure, Altered } \\
\text { Sensorium, } \\
\text { Septicemia, } \\
\text { Proptosis, } \\
\text { Hematemesis }\end{array}$ & $\begin{array}{l}\text { Mechanical } \\
\text { ventilation, } \\
\text { vasopressors, } \\
\text { renal } \\
\text { replacement } \\
\text { therapy, broad- } \\
\text { spectrum } \\
\text { antibiotics, } \\
\text { steroids, insulin }\end{array}$ & $\begin{array}{l}\text { Antifungals } \\
\text { not given }\end{array}$ & $\begin{array}{l}\text { CT Scan } \\
\text { Thorax and } \\
\text { paranasal } \\
\text { sinuses, KOH } \\
\text { test, RTPCR } \\
\text { Fungal } \\
\text { culture not } \\
\text { done }\end{array}$ & $\begin{array}{l}\text { COVID } \\
-19 \\
\text { RTPCR } \\
+\end{array}$ & $\begin{array}{l}\text { Pulmonary, } \\
\text { Rhino- } \\
\text { orbital }\end{array}$ & Death \\
\hline $\begin{array}{l}\text { Junior et } \\
\text { al }^{13}\end{array}$ & Brazil & 86 & $\begin{array}{l}\text { M } \\
\text { ale }\end{array}$ & $\begin{array}{l}\text { Case } \\
\text { report }\end{array}$ & Hypertension & $\begin{array}{l}\text { Cough, } \\
\text { Diarrhea, } \\
\text { Dyspnea, Fever, } \\
\text { Mild abdominal } \\
\text { tenderness }\end{array}$ & $\begin{array}{l}\text { Inj. Ceftriaxone, } \\
\text { tab } \\
\text { Azithromycin, } \\
\text { Tab } \\
\text { Oseltamivir, } \\
\text { Hydrocortisone }\end{array}$ & $\begin{array}{l}\text { Blood } \\
\text { transfusion, } \\
\text { Omeprazole }\end{array}$ & $\begin{array}{l}\text { CT chest, } \\
\text { Esophagogast } \\
\text { roduodenosco } \\
\text { py, } \\
\text { Pathological } \\
\text { examination }\end{array}$ & $\begin{array}{l}\text { COVID } \\
-19 \\
\text { RTPCR } \\
+\end{array}$ & $\begin{array}{l}\text { Gastrointest } \\
\text { inal }\end{array}$ & Death \\
\hline
\end{tabular}




\begin{tabular}{|c|c|c|c|c|c|c|c|c|c|c|c|c|}
\hline Authors & $\begin{array}{l}\text { Coun } \\
\text { try }\end{array}$ & $\begin{array}{l}\text { Age } \\
\text { in } \\
\text { years }\end{array}$ & $\begin{array}{l}\text { Se } \\
\mathbf{X}\end{array}$ & $\begin{array}{l}\text { Study } \\
\text { Design }\end{array}$ & $\begin{array}{l}\text { Comorbid } \\
\text { Illness }\end{array}$ & $\begin{array}{l}\text { Clinical } \\
\text { Presentation }\end{array}$ & $\begin{array}{l}\text { Treatment for } \\
\text { COVID-19 }\end{array}$ & $\begin{array}{l}\text { Specific } \\
\text { treatments }\end{array}$ & $\begin{array}{l}\text { Investigation } \\
\mathrm{S}\end{array}$ & $\begin{array}{l}\text { COVID } \\
-19 \\
\text { testing }\end{array}$ & $\begin{array}{l}\text { Type of } \\
\text { involvemen } \\
\mathrm{t} \text { in CAM }\end{array}$ & $\begin{array}{l}\text { Outco } \\
\text { me }\end{array}$ \\
\hline $\begin{array}{l}\text { Rabelo et } \\
\text { al }^{29}\end{array}$ & Brazil & 50 & $\begin{array}{l}\mathrm{Fe} \\
\mathrm{ma} \\
\text { le }\end{array}$ & $\begin{array}{l}\text { Case } \\
\text { Report }\end{array}$ & $\begin{array}{l}\text { Diabetes } \\
\text { mellitus }\end{array}$ & $\begin{array}{l}\text { Headache due to } \\
\text { COVID-19, } \\
\text { painful hard } \\
\text { palate lesion, }\end{array}$ & $\begin{array}{l}\text { Antibiotics, } \\
\text { NSAIDs }\end{array}$ & $\begin{array}{l}\text { Amphotericin- } \\
\text { B, } \\
\text { Hydrocortison } \\
\text { e, Surgical } \\
\text { debridement, } \\
\text { antihistamine } \\
\text { therapy, }\end{array}$ & $\begin{array}{l}\text { Incisional } \\
\text { biopsy, CT } \\
\text { scan, } \\
\text { Histopatholog } \\
\text { y, PAS test }\end{array}$ & $\begin{array}{l}\text { COVID } \\
-19 \\
\text { RTPCR } \\
+\end{array}$ & $\begin{array}{l}\text { Gastrointest } \\
\text { inal }\end{array}$ & Alive \\
\hline $\begin{array}{l}\text { Karimi- } \\
\text { Galougahi } \\
\text { et } \mathbf{a l}^{30}\end{array}$ & Iran & 61 & $\begin{array}{l}\mathrm{Fe} \\
\mathrm{ma} \\
\mathrm{le}\end{array}$ & $\begin{array}{l}\text { Case } \\
\text { report }\end{array}$ & $\begin{array}{l}\text { Diabetes } \\
\text { mellitus }\end{array}$ & $\begin{array}{l}\text { Hemifacial pain, } \\
\text { Rhinorrhea, } \\
\text { Chemosis, } \\
\text { Diabetic } \\
\text { Ketoacidosis, } \\
\text { Acute sinusitis }\end{array}$ & $\begin{array}{l}\text { Inj. Remdesivir, } \\
\text { Interferon- } \\
\text { alpha, Systemic } \\
\text { corticosteroid }\end{array}$ & $\begin{array}{l}\text { Insulin } \\
\text { therapy, } \\
\text { Systemic } \\
\text { antifungals, } \\
\text { FESS, } \\
\text { Exenteration }\end{array}$ & $\begin{array}{l}\text { CT paranasal } \\
\text { sinuses, MRI } \\
\text { orbits, Sino- } \\
\text { nasal } \\
\text { endoscopy }\end{array}$ & $\begin{array}{l}\text { COVID } \\
-19 \\
\text { RTPCR } \\
+\end{array}$ & $\begin{array}{l}\text { Rhino- } \\
\text { orbital }\end{array}$ & $\begin{array}{l}\text { Not } \\
\text { known }\end{array}$ \\
\hline $\begin{array}{l}\text { Rezaie et } \\
\text { al }^{31}\end{array}$ & Iran & $\begin{array}{l}53.75 \\
\text { (mean } \\
\text { ) } \\
\pm 19.7 \\
5 \\
\mathrm{n}=7\end{array}$ & $\begin{array}{l}\text { M } \\
\text { ale } \\
- \\
6, \\
\mathrm{Fe} \\
\mathrm{ma} \\
\mathrm{le}- \\
1\end{array}$ & $\begin{array}{l}\text { Case } \\
\text { present } \\
\text { ation \& } \\
\text { review } \\
\text { article }\end{array}$ & $\begin{array}{l}\text { Uncontrolled } \\
\text { diabetes } \\
\text { mellitus-3, } \\
\text { Hypertension- } \\
\text { 4,Bronchial } \\
\text { asthma- 1, } \\
\text { Pancreatitis- 1, } \\
\text { Hyperlipidemi } \\
\text { a- } 1\end{array}$ & Severe ARDS & $\begin{array}{l}\text { Oxygen } \\
\text { supplementation } \\
\text { with mechanical } \\
\text { ventilation, } \\
\text { systemic } \\
\text { corticosteroids, }\end{array}$ & $\begin{array}{l}\text { Antifungal } \\
\text { monotherapy } \\
(43 \%), \\
\text { Combined } \\
\text { antifungal } \\
\text { therapy } \\
(28.57 \%), \\
\text { surgical } \\
\text { intervention } \\
\text { (in } 4 \text { patients) }\end{array}$ & $\begin{array}{l}\text { Blood culture, } \\
\mathrm{KOH} \\
\text { examination, } \\
\mathrm{Ct} \text { scan } \\
\text { paranasal } \\
\text { sinus }\end{array}$ & $\begin{array}{l}\text { COVID } \\
-19 \\
\text { RTPCR } \\
+\end{array}$ & $\begin{array}{l}\text { Rhino- } \\
\text { orbital- } \\
\text { cerebral- } 2 \\
\text { Others- } 5\end{array}$ & $\begin{array}{l}\text { Death- } \\
7\end{array}$ \\
\hline \multirow[t]{2}{*}{ Veisi et $\mathbf{a l}^{32}$} & \multirow[t]{2}{*}{ Iran } & 40 & $\begin{array}{l}\mathrm{Fe} \\
\mathrm{ma} \\
\mathrm{le}\end{array}$ & $\begin{array}{l}\text { Case } \\
\text { report }\end{array}$ & $\begin{array}{l}\text { No h/o ARDS, } \\
\text { immune } \\
\text { system } \\
\text { disorders, or } \\
\text { any chronic } \\
\text { conditions }\end{array}$ & $\begin{array}{l}\text { Blepharoptosis, } \\
\text { Ophthalmoplegi } \\
\text { a, Proptosis, }\end{array}$ & $\begin{array}{l}\text { Supplemental } \\
\text { oxygen, } \\
\text { Remdesivir, } \\
\text { Levofloxacin, } \\
\text { Dexamethasone, } \\
\text { Meropenem, } \\
\text { Vancomycin, }\end{array}$ & $\begin{array}{l}\text { Refused } \\
\text { surgery. The } \\
\text { patient was on } \\
\text { regular } \\
\text { paranasal } \\
\text { sinus } \\
\text { debridement }\end{array}$ & $\begin{array}{l}\text { CT scan orbit, } \\
\text { MRI, } \\
\text { Histopatholog } \\
\text { y, H\&E } \\
\text { staining test }\end{array}$ & $\begin{array}{l}\text { RTPCR } \\
+\end{array}$ & $\begin{array}{l}\text { Rhino- } \\
\text { orbital- } \\
\text { cerebral }\end{array}$ & Death \\
\hline & & 54 & $\begin{array}{l}\text { M } \\
\text { ale }\end{array}$ & $\begin{array}{l}\text { Case } \\
\text { report }\end{array}$ & $\begin{array}{l}\text { Diabetes } \\
\text { mellitus }\end{array}$ & $\begin{array}{l}\text { Blepharoptosis, } \\
\text { Proptosis, } \\
\text { Chemosis, Mild } \\
\text { conjunctival } \\
\text { infection }\end{array}$ & $\begin{array}{l}\text { Supplemental } \\
\text { oxygen, } \\
\text { Remdesivir, } \\
\text { Levofloxacin, } \\
\text { Piperacillin- } \\
\text { Tazobactum, }\end{array}$ & $\begin{array}{l}\text { FESS, } \\
\text { Amphotericin- } \\
\text { B, Insulin } \\
\text { therapy, } \\
\text { Dexamethason } \\
\text { e, }\end{array}$ & $\begin{array}{l}\text { CT Scan, } \\
\text { MRI, } \\
\text { Histopatholog } \\
\text { y }\end{array}$ & $\begin{array}{l}\text { RTPCR } \\
+\end{array}$ & $\begin{array}{l}\text { Rhino- } \\
\text { orbital }\end{array}$ & Alive \\
\hline
\end{tabular}




\begin{tabular}{|c|c|c|c|c|c|c|c|c|c|c|c|c|}
\hline Authors & $\begin{array}{l}\text { Coun } \\
\text { try }\end{array}$ & $\begin{array}{l}\text { Age } \\
\text { in } \\
\text { years }\end{array}$ & $\begin{array}{l}\text { Se } \\
\mathbf{x}\end{array}$ & $\begin{array}{l}\text { Study } \\
\text { Design }\end{array}$ & $\begin{array}{l}\text { Comorbid } \\
\text { Illness }\end{array}$ & $\begin{array}{l}\text { Clinical } \\
\text { Presentation }\end{array}$ & $\begin{array}{l}\text { Treatment for } \\
\text { COVID-19 }\end{array}$ & $\begin{array}{l}\text { Specific } \\
\text { treatments }\end{array}$ & $\begin{array}{l}\text { Investigation } \\
\mathrm{s}\end{array}$ & $\begin{array}{l}\text { COVID } \\
-19 \\
\text { testing }\end{array}$ & $\begin{array}{l}\text { Type of } \\
\text { involvemen } \\
t \text { in CAM }\end{array}$ & $\begin{array}{l}\text { Outco } \\
\text { me }\end{array}$ \\
\hline & & & & & & & Vancomycin, & Posaconazole & & & & \\
\hline $\begin{array}{l}\text { Pasero et } \\
\mathrm{al}^{33}\end{array}$ & Italy & 66 & $\begin{array}{l}\mathrm{M} \\
\text { ale }\end{array}$ & $\begin{array}{l}\text { Case } \\
\text { report }\end{array}$ & $\begin{array}{l}\text { Hypertension, } \\
\text { Urinary tract } \\
\text { infection }\end{array}$ & Hypoxia & $\begin{array}{l}\text { Inj. } \\
\text { Hydroxychloroq } \\
\text { uine, } \\
\text { Lopinavir+ } \\
\text { Ritonavir, } \\
\text { Mechanical } \\
\text { ventilation, } \\
\text { Piperacillin+ } \\
\text { Tazobactum, } \\
\text { Levofloxacin }\end{array}$ & $\begin{array}{l}\text { Amphotericin- } \\
\mathrm{B} \text {, inj. } \\
\text { Isovuconazole } \\
\text { Thoracentesis }\end{array}$ & $\begin{array}{l}\text { CBC, } \\
\text { Bronchial } \\
\text { aspirate, } \\
\text { SDA, CT } \\
\text { scan, }\end{array}$ & $\begin{array}{l}\text { COVID } \\
+\end{array}$ & Pulmonary & Death \\
\hline $\begin{array}{l}\text { Waizel- } \\
\text { Haiat et } \\
\text { al }^{12}\end{array}$ & $\begin{array}{l}\text { Mexi } \\
\text { co }\end{array}$ & 24 & $\begin{array}{l}\mathrm{Fe} \\
\mathrm{ma} \\
\mathrm{le}\end{array}$ & $\begin{array}{l}\text { Case } \\
\text { report }\end{array}$ & $\begin{array}{l}\text { Obesity, } \\
\text { Diabetes } \\
\text { mellitus }\end{array}$ & $\begin{array}{l}\text { Respiratory } \\
\text { Failure, Left } \\
\text { eyelid edema, } \\
\text { Ptosis, Pallor } \\
\text { hard palate }\end{array}$ & $\begin{array}{l}\text { Inj. Imipenem/ } \\
\text { Linezolid }\end{array}$ & $\begin{array}{l}\text { Amphotericin- } \\
\text { B }\end{array}$ & $\begin{array}{l}\text { CT scan orbit, } \\
\text { paranasal } \\
\text { sinuses, and } \\
\text { chest, CBC, } \\
\text { LFT, KFT, D- } \\
\text { dimer, } \\
\text { Tracheal } \\
\text { secretion } \\
\text { culture, } \\
\text { fungal culture }\end{array}$ & $\begin{array}{l}\text { COVID } \\
-19 \\
\text { RTPCR } \\
+\end{array}$ & $\begin{array}{l}\text { Rhino- } \\
\text { orbital }\end{array}$ & Death \\
\hline $\begin{array}{l}\text { Alekseyev } \\
\text { et } \mathbf{a l}^{34}\end{array}$ & U.S.A & 41 & $\begin{array}{l}\text { M } \\
\text { ale }\end{array}$ & $\begin{array}{l}\text { Case } \\
\text { report }\end{array}$ & $\begin{array}{l}\text { Diabetes } \\
\text { mellitus I, } \\
\text { Hypertension }\end{array}$ & $\begin{array}{l}\text { Dry cough, Loss } \\
\text { of taste, Nasal } \\
\text { pain }\end{array}$ & $\begin{array}{l}\text { Steroids, } \\
\text { Hydroxychloroq } \\
\text { uine, }\end{array}$ & $\begin{array}{l}\text { Insulin } \\
\text { therapy, } \\
\text { Cefepime, } \\
\text { Amphotericin- } \\
\text { B, Surgical } \\
\text { debridement, } \\
\text { Heparin }\end{array}$ & $\begin{array}{l}\text { X-ray chest, } \\
\text { CT scan, } \\
\text { MRI, LFT, } \\
\text { KFT, S. } \\
\text { electrolytes, } \\
\text { S. ferritin, } \\
\text { G6PD, fungal } \\
\text { culture }\end{array}$ & $\begin{array}{l}\text { COVID } \\
-19 \\
\text { RTPCR } \\
+\end{array}$ & $\begin{array}{l}\text { Rhino- } \\
\text { cerebral }\end{array}$ & Alive \\
\hline
\end{tabular}




\begin{tabular}{|c|c|c|c|c|c|c|c|c|c|c|c|c|}
\hline Authors & $\begin{array}{l}\text { Coun } \\
\text { try }\end{array}$ & $\begin{array}{l}\text { Age } \\
\text { in } \\
\text { years }\end{array}$ & $\begin{array}{l}\text { Se } \\
\mathbf{X}\end{array}$ & $\begin{array}{l}\text { Study } \\
\text { Design }\end{array}$ & $\begin{array}{l}\text { Comorbid } \\
\text { Illness }\end{array}$ & $\begin{array}{l}\text { Clinical } \\
\text { Presentation }\end{array}$ & $\begin{array}{l}\text { Treatment for } \\
\text { COVID-19 }\end{array}$ & $\begin{array}{l}\text { Specific } \\
\text { treatments }\end{array}$ & $\begin{array}{l}\text { Investigation } \\
\mathrm{S}\end{array}$ & $\begin{array}{l}\text { COVID } \\
-19 \\
\text { testing }\end{array}$ & $\begin{array}{l}\text { Type of } \\
\text { involvemen } \\
t \text { in CAM }\end{array}$ & $\begin{array}{l}\text { Outco } \\
\text { me }\end{array}$ \\
\hline $\begin{array}{l}\text { Kanwar et } \\
\text { al }^{35}\end{array}$ & U.S.A & 56 & $\begin{array}{l}\text { M } \\
\text { ale }\end{array}$ & $\begin{array}{l}\text { Case } \\
\text { report }\end{array}$ & $\begin{array}{l}\text { End-stage } \\
\text { renal disease, } \\
\text { h/o } \\
\text { hemodialysis }\end{array}$ & $\begin{array}{l}\text { Fatigue, } \\
\text { shortness of } \\
\text { breath, } \\
\text { Hemoptysis }\end{array}$ & $\begin{array}{l}\text { Methylprednisol } \\
\text { one, Inj. } \\
\text { Tocilizumab, } \\
\text { Convalescent } \\
\text { plasma, Inj. } \\
\text { Vancomycin, } \\
\text { Inj. piperacillin } \\
\text {-Tazobactum }\end{array}$ & $\begin{array}{l}\text { Inj. Liposomal } \\
\text { Amphotericin } \\
\text { B, }\end{array}$ & $\begin{array}{l}\text { Chest Xray, } \\
\text { CT Chest, } \\
\text { USG Guided } \\
\text { Thoracocente } \\
\text { sis, Sputum } \\
\text { culture on } \\
\text { SDA slant, } \\
\text { Histopatholog } \\
\text { ical } \\
\text { examination } \\
\text { of parietal } \\
\text { pleura, PAS } \\
\text { staining, }\end{array}$ & $\begin{array}{l}\text { COVID } \\
-19 \\
\text { RTPCR } \\
+\end{array}$ & Pulmonary & Death \\
\hline $\begin{array}{l}\text { Cockerha } \\
\text { m et } \mathbf{a l}^{36}\end{array}$ & U.S.A & 35 & $\begin{array}{l}\text { M } \\
\text { ale }\end{array}$ & $\begin{array}{l}\text { Case } \\
\text { report }\end{array}$ & $\begin{array}{l}\text { MRSA, } \\
\text { Uncontrolled } \\
\text { Diabetes } \\
\text { Mellitus I, } \\
\text { Diabetic } \\
\text { nephropathy }\end{array}$ & $\begin{array}{l}\text { Diabetic } \\
\text { ketoacidosis, } \\
\text { headache, } \\
\text { altered mental } \\
\text { status, left eye } \\
\text { pain }\end{array}$ & $\begin{array}{l}\text { Ampicillin+ } \\
\text { Sulbactum, } \\
\text { Remdesivir, } \\
\text { Dexamethasone }\end{array}$ & $\begin{array}{l}\text { Amphotericin- } \\
\text { B, Surgical } \\
\text { debridement } \\
\text { of necrotic } \\
\text { tissue }\end{array}$ & $\begin{array}{l}\text { ESR, CRP, } \\
\text { D-dimer, CT } \\
\text { scan orbits, } \\
\text { MRI orbits, } \\
\text { nasal } \\
\text { endoscopy }\end{array}$ & $\begin{array}{l}\text { COVID } \\
+\end{array}$ & $\begin{array}{l}\text { Rhino- } \\
\text { orbital- } \\
\text { cerebral }\end{array}$ & Alive \\
\hline $\begin{array}{l}\text { Dallalzade } \\
\text { h et } \text { al }^{37}\end{array}$ & U.S.A & 36 & $\begin{array}{l}\text { M } \\
\text { ale }\end{array}$ & $\begin{array}{l}\text { Case } \\
\text { Report }\end{array}$ & $\begin{array}{l}\text { Diabetes } \\
\text { mellitus }\end{array}$ & $\begin{array}{l}\text { Left facial } \\
\text { swelling } \\
\text {,sinusitis, } \\
\text {,Diabetic } \\
\text { ketoacidosis }\end{array}$ & $\begin{array}{l}\text { Oral antibiotics, } \\
\text { Corticosteroids, } \\
\text { Inj. Remdesivir }\end{array}$ & $\begin{array}{l}\text { Lateral } \\
\text { canthotomy } \\
\text { and } \\
\text { cantholysis, } \\
\text { Endoscopic } \\
\text { sinus } \\
\text { debridement, } \\
\text { Inj. } \\
\text { Amphotericin, } \\
\text { inj. } \\
\text { Isavuconazole, } \\
\text { inj. } \\
\text { micafungin }\end{array}$ & $\begin{array}{l}\text { Ophthalmic } \\
\text { examination, } \\
\text { fundoscopic } \\
\text { exam, MRI } \\
\text { Face and } \\
\text { brain, chest } \\
\text { X-ray, fungal } \\
\text { culture }\end{array}$ & $\begin{array}{l}\text { COVID } \\
-19 \\
\text { RTPCR } \\
+\end{array}$ & $\begin{array}{l}\text { Rhino- } \\
\text { orbital }\end{array}$ & Death \\
\hline
\end{tabular}




\begin{tabular}{|c|c|c|c|c|c|c|c|c|c|c|c|c|}
\hline Authors & $\begin{array}{l}\text { Coun } \\
\text { try }\end{array}$ & $\begin{array}{l}\text { Age } \\
\text { in } \\
\text { years }\end{array}$ & $\begin{array}{l}\text { Se } \\
\mathbf{x}\end{array}$ & $\begin{array}{l}\text { Study } \\
\text { Design }\end{array}$ & $\begin{array}{l}\text { Comorbid } \\
\text { Illness }\end{array}$ & $\begin{array}{l}\text { Clinical } \\
\text { Presentation }\end{array}$ & $\begin{array}{l}\text { Treatment for } \\
\text { COVID-19 }\end{array}$ & $\begin{array}{l}\text { Specific } \\
\text { treatments }\end{array}$ & $\begin{array}{l}\text { Investigation } \\
\mathrm{S}\end{array}$ & $\begin{array}{l}\text { COVID } \\
-19 \\
\text { testing }\end{array}$ & $\begin{array}{l}\text { Type of } \\
\text { involvemen } \\
t \text { in CAM }\end{array}$ & $\begin{array}{l}\text { Outco } \\
\text { me }\end{array}$ \\
\hline & & 48 & $\begin{array}{l}\text { M } \\
\text { ale }\end{array}$ & $\begin{array}{l}\text { Case } \\
\text { Report }\end{array}$ & $\begin{array}{l}\text { Diabetes } \\
\text { mellitus, } \\
\text { COVID19 } \\
\text { Pneumonitis, } \\
\text { Diabetic } \\
\text { ketoacidosis }\end{array}$ & $\begin{array}{l}\text { periorbital } \\
\text { edema, purulent } \\
\text { discharge }\end{array}$ & $\begin{array}{l}\text { Inj. Remdesivir, } \\
\text { Convalescent } \\
\text { plasma. } \\
\text { Dexamethasone }\end{array}$ & $\begin{array}{l}\text { Inj. } \\
\text { Amphotericin } \\
\mathrm{B}, \text { Inj. } \\
\text { Isovuconazole }\end{array}$ & $\begin{array}{l}\text { CT Scan face } \\
\text { and brain, } \\
\text { fungus } \\
\text { culture of } \\
\text { purulent } \\
\text { discharge }\end{array}$ & $\begin{array}{l}\text { COVID } \\
+\end{array}$ & $\begin{array}{l}\text { Rhino- } \\
\text { orbital- } \\
\text { cerebral }\end{array}$ & Alive \\
\hline $\begin{array}{l}\text { Johnson et } \\
\text { al }^{38}\end{array}$ & U.S.A & 79 & $\begin{array}{l}\text { M } \\
\text { ale }\end{array}$ & $\begin{array}{l}\text { Case } \\
\text { report }\end{array}$ & $\begin{array}{l}\text { Diabetes } \\
\text { mellitus, } \\
\text { Hypertension }\end{array}$ & $\begin{array}{l}\text { Fever, rigors, } \\
\text { dry cough, } \\
\text { shortness of } \\
\text { breath }\end{array}$ & $\begin{array}{l}\text { Inj. Ceftriaxone, } \\
\text { Inj. } \\
\text { Azithromycin, } \\
\text { Inj. Remdesivir, } \\
\text { inj. } \\
\text { Dexamethasone, } \\
\text { Vancomycin, } \\
\text { inj. } \\
\text { Norepinephrine }\end{array}$ & $\begin{array}{l}\text { inj. } \\
\text { Voriconazole, } \\
\text { iv L- } \\
\text { Amphotericin } \\
\text { B ,inj. Insulin }\end{array}$ & $\begin{array}{l}\text { Chest X-ray, } \\
\text { CT chest, } \\
\text { Microscopic } \\
\text { examination } \\
\text { of BAL } \\
\text { specimen, } \\
\text { KOH } \\
\text { Microscopic } \\
\text { examination, } \\
\text { a culture of } \\
\text { BAL } \\
\text { specimen }\end{array}$ & $\begin{array}{l}\text { Covid- } \\
19 \\
\text { RTPCR } \\
+\end{array}$ & $\begin{array}{l}\text { Pulmonary } \\
\text { mucormyco } \\
\text { sis }\end{array}$ & Alive \\
\hline $\begin{array}{l}\text { Khan et } \\
\text { al }^{39}\end{array}$ & U.S.A & 44 & $\begin{array}{l}\mathrm{Fe} \\
\mathrm{ma} \\
\mathrm{le}\end{array}$ & $\begin{array}{l}\text { Case } \\
\text { report }\end{array}$ & Hypertension, & ARDS & $\begin{array}{l}\text { Inj. Remdesivir, } \\
\text { Methylprednisol } \\
\text { one, Mechanical } \\
\text { ventilation, }\end{array}$ & $\begin{array}{l}\text { Insulin } \\
\text { therapy, } \\
\text { Voriconazole, } \\
\text { Piperacillin+ } \\
\text { Tazobactum, } \\
\text { Micafungin }\end{array}$ & $\begin{array}{l}\text { CBC, CRP, S. } \\
\text { Electrolytes, } \\
\text { D-dimer, } \\
\text { LFT, S. } \\
\text { ferritin, } \\
\text { Tracheal } \\
\text { aspirate } \\
\text { culture, } \\
\text { Bronchoscop } \\
\text { y }\end{array}$ & $\begin{array}{l}\text { COVID } \\
+\end{array}$ & Pulmonary & Death \\
\hline $\begin{array}{l}\text { Khatri et } \\
\text { al }^{40}\end{array}$ & U.S.A & 68 & $\begin{array}{l}\text { M } \\
\text { ale }\end{array}$ & $\begin{array}{l}\text { Case } \\
\text { report }\end{array}$ & $\begin{array}{l}\text { h/o Heart } \\
\text { transplant, } \\
\text { Diabetes } \\
\text { mellitus, } \\
\text { Hypertension, } \\
\text { Chronic, } \\
\text { kidney disease }\end{array}$ & $\begin{array}{l}\text { Cough, } \\
\text { Diarrhea, Fever, } \\
\text { Sternal wound } \\
\text { discharge }\end{array}$ & $\begin{array}{l}\text { Inj. Remdesivir } \\
\text {, plasma } \\
\text { infusion } \\
\text {,inj. } \\
\text { Vancomycin, } \\
\text { Inj. Meropenem } \\
\text {,inj. }\end{array}$ & $\begin{array}{l}\text { Iv } \\
\text { Amphotericin } \\
\text { B, Inj. } \\
\text { Posaconazole, } \\
\text { Debridement } \\
\text { of the thoracic } \\
\text { cavity }\end{array}$ & $\begin{array}{l}\text { Chest CT } \\
\text { scan, fungal } \\
\text { culture }\end{array}$ & $\begin{array}{l}\text { COVID } \\
19 \\
\text { RTPCR } \\
+\end{array}$ & Cutaneous & Death \\
\hline
\end{tabular}




\begin{tabular}{|c|c|c|c|c|c|c|c|c|c|c|c|c|}
\hline Authors & $\begin{array}{l}\text { Coun } \\
\text { try }\end{array}$ & $\begin{array}{l}\text { Age } \\
\text { in } \\
\text { years }\end{array}$ & $\begin{array}{l}\text { Se } \\
\mathbf{X}\end{array}$ & $\begin{array}{l}\text { Study } \\
\text { Design }\end{array}$ & $\begin{array}{l}\text { Comorbid } \\
\text { Illness }\end{array}$ & $\begin{array}{l}\text { Clinical } \\
\text { Presentation }\end{array}$ & $\begin{array}{l}\text { Treatment for } \\
\text { COVID-19 }\end{array}$ & $\begin{array}{l}\text { Specific } \\
\text { treatments }\end{array}$ & $\begin{array}{l}\text { Investigation } \\
\mathrm{S}\end{array}$ & $\begin{array}{l}\text { COVID } \\
-19 \\
\text { testing }\end{array}$ & $\begin{array}{l}\text { Type of } \\
\text { involvemen } \\
\mathrm{t} \text { in CAM }\end{array}$ & $\begin{array}{l}\text { Outco } \\
\text { me }\end{array}$ \\
\hline & & & & & & & $\begin{array}{l}\text { cyclosporine, } \\
\text { methylprednisol } \\
\text { one, } \\
\text { hemodialysis }\end{array}$ & & & & & \\
\hline $\begin{array}{l}\text { Mekonnen } \\
\text { et } \text { al }^{41}\end{array}$ & U.S.A & 60 & $\begin{array}{l}\mathrm{M} \\
\text { ale }\end{array}$ & $\begin{array}{l}\text { Case } \\
\text { report }\end{array}$ & $\begin{array}{l}\text { Uncontrolled } \\
\text { diabetes } \\
\text { mellitus, } \\
\text { Hypertension, } \\
\text { Asthma, } \\
\text { Hyperlipidemi } \\
\text { a }\end{array}$ & $\begin{array}{l}\text { Dyspnea, } \\
\text { Hypoxia }\end{array}$ & $\begin{array}{l}\text { Inj. Remdesivir, } \\
\text { iv Vancomycin, } \\
\text { Inj. Cefepime, } \\
\text { Inj. } \\
\text { Dexamethasone, } \\
\text { plasma }\end{array}$ & $\begin{array}{l}\text { Inj. } \\
\text { Amphotericin } \\
\text { B, Inj. } \\
\text { Caspofungin, } \\
\text { Retrobulbar } \\
\text { inj. } \\
\text { amphotericin } \\
\text { B, Inj. } \\
\text { Posaconazole }\end{array}$ & $\begin{array}{l}\text { CT brain, } \\
\text { orbit, and } \\
\text { neck }\end{array}$ & $\begin{array}{l}\text { COVID } \\
-19 \\
\text { RTPCR } \\
+\end{array}$ & $\begin{array}{l}\text { Rhino- } \\
\text { orbital }\end{array}$ & Death \\
\hline $\begin{array}{l}\text { Placik et } \\
\text { al }^{42}\end{array}$ & U.S.A & 49 & $\begin{array}{l}\mathrm{M} \\
\text { ale }\end{array}$ & $\begin{array}{l}\text { Case } \\
\text { report }\end{array}$ & $\begin{array}{l}\text { No medical } \\
\text { history }\end{array}$ & $\begin{array}{l}\text { Fever, Cough, } \\
\text { Dyspnea, }\end{array}$ & $\begin{array}{l}\text { Oxygen } \\
\text { supplementation } \\
\text {, Ceftriaxone, } \\
\text { Azithromycin, } \\
\text { Enoxaparin, } \\
\text { Dexamethasone, } \\
\text { Inj. Remdesivir, } \\
\text { Tocilizumab }\end{array}$ & $\begin{array}{l}\text { Amphotericin- } \\
\mathrm{B}, \text { Mechanical } \\
\text { ventilation }\end{array}$ & $\begin{array}{l}\text { X-ray chest, } \\
\text { CBC, CRP, } \\
\text { LDH, Serum } \\
\text { ferritin, D- } \\
\text { dimer, fungal } \\
\text { culture }\end{array}$ & $\begin{array}{l}\text { COVID } \\
-19 \\
\text { RTPCR } \\
+\end{array}$ & Pulmonary & Death \\
\hline $\begin{array}{l}\text { Werthman } \\
\text { et } \mathbf{a l}^{43}\end{array}$ & $\begin{array}{l}\text { U.S.A } \\
\text {. }\end{array}$ & 33 & $\begin{array}{l}\mathrm{Fe} \\
\mathrm{ma} \\
\mathrm{le}\end{array}$ & $\begin{array}{l}\text { Case } \\
\text { report }\end{array}$ & $\begin{array}{l}\text { Hypertension, } \\
\text { Asthma, } \\
\text { Diabetic } \\
\text { ketoacidosis }\end{array}$ & $\begin{array}{l}\text { Altered mental } \\
\text { status, Cough, } \\
\text { Dyspnea, } \\
\text { Vomiting, Left } \\
\text { eye ptosis }\end{array}$ & $\begin{array}{l}\text { Inj. } \\
\text { vancomycin, } \\
\text { Inj. } \\
\text { Piperacillin+ } \\
\text { Tazobactam, } \\
\text { Inj. Remdesivir } \\
\text { Plasma }\end{array}$ & $\begin{array}{l}\text { Inj. } \\
\text { Amphotericin- } \\
\mathrm{B} \text {, sinus } \\
\text { debridement }\end{array}$ & $\begin{array}{l}\text { Chest X-ray, } \\
\text { CT head, face } \\
\text { and orbit, } \\
\text { Culture for } \\
\text { fungus, MRI } \\
\text { brain }\end{array}$ & $\begin{array}{l}\text { COVID } \\
19 \\
\text { RTPCR } \\
+\end{array}$ & $\begin{array}{l}\text { Rhino- } \\
\text { orbital } \\
\text { cerebral }\end{array}$ & Death \\
\hline
\end{tabular}


The youngest patient was 24 years and the eldest was 86 years. According to a previous study, 11 India has the highest burden of mucormycosis cases in the world with an estimated prevalence of 140 cases per million population. ${ }^{13} 75.7 \%$ were male and $24.3 \%$ were female. ${ }^{12}$ All reported cases in our review were COVID-19 positive. Some patients had an active infection, while others had recovered or were in the recovery phase. The diagnosis was established mainly by radiological features, histopathological examination, microbiological, and culture for fungus.

In our systemic review analysis 72/104 (69.9\%) cases had diabetes mellitus (DM II) and 11/104 (10.6\%) cases had diabetic ketoacidosis (DKA), 30/104 (29.1\%) cases hypertension (HTN), 7/104 $(6.7 \%)$ had a renal failure (RF) $4 / 104(3.8 \%)$ had coronary artery disease (CAD), $2 / 104(1.9 \%)$ had a history of dialysis, and 2/104 (1.9\%) had chronic liver disease (CLD). In our review, the clinical presentation of mucormycosis was consistent with the picture of mucormycosis in DM II where the predominant clinical presentation was rhino-orbital or rhino-cerebral disease predominates and DM II is the most common risk factor for mucormycosis and is associated with increased morbidity and mortality in COVID19. ${ }^{11}$

In our study, out of 104 confirmed cases of mucormycosis, 74/104 $(71.8 \%)$ cases received corticosteroid during COVID-19 treatment. In a previous study on 101 mucormycosis cases (95 confirmed and 6 suspected cases) in COVID-19, 80\% of cases had DM II and $76.3 \%$ received a course of intravenous corticosteroids. ${ }^{11}$ Similarly, in a systemic review, 41 confirmed reported cases in people with COVID-19, 93\% cases were reported with DM II, while $88 \%$ were received intravenous corticosteroids. ${ }^{14}$ Whereas a study conducted before the COVID-19 pandemic, a nationwide multicentre study of 388 cases of diagnosed/suspected mucormycosis in India, finds that $57 \%$ had uncontrolled DM II and $18 \%$ had DKA. ${ }^{5,14}$ Corticosteroid use is a key factor for opportunistic mycoses, including mucormycosis, and frequent use of corticosteroid causes hyperglycemia. ${ }^{11}$ A previous study reported that COVID 19 positive patients are highly susceptible to mucormycosis who are under high steroid doses or in immunosuppressive therapy. ${ }^{15}$

In addition to hyperglycemia, altered iron metabolism occurs in severe COVID 19 cases. There is a hyperferritinemic state; high ferritin is a marker of severe systemic disease. High ferritin level leads to excess intracellular iron that generates reactive oxygen species resulting in tissue damage. Cytokines, especially Interleukin-6 (IL-6), due to severe infection and DKA, stimulates ferritin synthesis; downregulates iron export resulting in intracellular iron overload, further exacerbating the process. Therefore, iron overload and excess free iron seen in acidemic states are one risk factor for mucormycosis. ${ }^{11}$
In our review, $55.3 \%$ of cases had rhino-orbital mucormycosis (ROM), 9.62\% cases had pulmonary mucormycosis (PM), 31.0\% had rhino-orbital-cerebral mucormycosis (ROCM), $1.9 \%$ had gastrointestinal mucormycosis (GM), and $0.9 \%$ had cutaneous mucormycosis (CM). Whereas in another study, $88.9 \%$ had nose and sinus involvement followed by $56.7 \%$ had rhino-orbital mucormycosis, $22.2 \%$ had rhino-orbitalcerebral mucormycosis. ${ }^{14}$ In another study in India before the COVID-19 pandemic, of 465 cases of mucormycosis $67.7 \%$ patients had shown rhino-orbital mucormycosis as the most common presentation, followed by $13.3 \%$ as pulmonary and $10.5 \%$ exhibiting cutaneous type mucormycosis. ${ }^{6}$

Hyperglycemia and ketoacidosis enhance the expression of endothelial receptor glucose-regulated protein (GRP 78) and the mucorales spore coat protein homologs $(\mathrm{CotH})$, which causes increased susceptibility of diabetic ketoacidosis patients to mucormycosis. ${ }^{11,16}$

In our review, intravenous liposomal Amphotericin-B has been used in $82.5 \%$ of cases of mucormycosis. It was found that a combination of antifungal agents was used in $19.4 \%$ of participants, and the most common combination used was Posaconazole $15.5 \%$ along with intravenous liposomal Amphotericin-B.

In our review, the combined medical and surgical management was performed in $79.6 \%$ of the cases. The overall mortality in our review was $36.9 \%$. Whereas in another study, $1430.7 \%$ overall mortality was reported.

The presence of multiple comorbid conditions in COVID-19 positive patients, additional immunosuppression caused by glucocorticoids predisposing patients to invasive fungal infection. The current guideline for the management of mucormycosis suggests intravenous liposomal Amphotericin B at 5-10 $\mathrm{mg} / \mathrm{kg}$ per day and up to $10 \mathrm{mg} / \mathrm{kg}$ per day in cases of central nervous system involvement. ${ }^{17}$

Control of hyperglycemia, judicious use of steroids, early diagnosis and treatment with intravenous liposomal Amphotericin-B, as well as surgical debridement, are all necessary for a successful outcome. ${ }^{18}$

\section{Limitations}

The sample size of the patients in the review was small and a large group is needed to draw adequate conclusions. We could not rule out publication bias as our study is based on reported cases. Duration of hospital stay, total duration of therapy, and duration of follow-ups were not uniformly documented in the published materials. Mucormycosis attributable mortality was not estimated due to a lack of acceptable and sufficient controls in the study. As a result of which, we could not exactly predict the associated risk factor leading to the development of CAM in COVID-19 positive patients. 
Further, in absence of a denominator, we were unable to calculate the exact incidence of COVID-associated mucormycosis.

\section{CONCLUSION}

The diagnosis of mucormycosis is still challenging and very dynamic. In our study, we found that most cases were reported from India. All patients had a history of COVID-19 infection, and most patients were diabetic and received corticosteroid therapy during treatment of COVID-19, which suggests rationale use of the drug during the pandemic. Combined antifungal and surgical treatment may be associated with an increased survival rate. In the future, all clinicians should be aware of the possibility of fungal infections such as mucormycosis developing in COVID-19 patients, particularly those with comorbidities and who are on immunosuppressive drugs. Early diagnosis and intravenous liposomal Amphotericin therapy, as well as surgical intervention, are vital for a better outcome of the disease. To gain a better understanding of the novel viral infection and the associated coinfections, global scientific collaboration and publication of new findings are critical.

\section{Future considerations}

The findings from the review study implicate the requirements to consider necessary updates in the management of CAM that can be shared among healthcare professionals to provide and promote a holistic treatment model globally. The efficiency of early diagnosis and treatment can be inculcated in future research and policymaking to ensure adequate accessible information to minimize the impact of the disease.

\section{ACKNOWLEDGEMENTS}

The authors would like to thank all the frontline healthcare workers' all over the world engaged in managing the COVID-19 pandemic.

\section{Funding: No funding sources}

Conflict of interest: None declared

Ethical approval: Not required

\section{REFERENCES}

1. Mehta S, Pandey A. Rhino-Orbital Mucormycosis Associated With COVID-19. Cureus. 2020;12(9).

2. Ismaiel WF, H. MA, Eldsoky I, Ibrahim AA. The impact of COVID-19 outbreak on the incidence of acute invasive fungal rhinosinusitis. Am J Otolaryngol. Published online 2021.

3. Petrikkos G, Tsioutis C. Recent Advances in the Pathogenesis of Mucormycoses. Clin Ther. 2018;40(6):894-902.

4. Omara F 0, Blakley BR. The effects of iron deficiency and iron overload on cell-mediated immunity in the mouse. Br J o j Nutr. 2021;72:899909.

5. Prakash H, Chakrabarti A. Epidemiology of Mucormycosis in India. Published online 2021:1-12.

6. Patel A, Kaur H, Xess I. A multicentre observational study on the epidemiology, risk factors, management and outcomes of mucormycosis in India. Clin Microbiol Infect. 2020;26(7):944.e9-944.e15.

7. Sharma S, Grover M, Bhargava S, Samdani S, Kataria T. Post coronavirus disease mucormycosis: a deadly addition to the pandemic spectrum. J Laryngol Otol. 2021;1-6.

8. Moorthy A, Gaikwad R, Krishna S. SARS-CoV-2, Uncontrolled Diabetes and Corticosteroids-An Unholy Trinity in Invasive Fungal Infections of the Maxillofacial Region? A Retrospective, Multicentric Analysis. J Maxillofac Oral Surg. 2021;2.

9. Page MJ, Mckenzie JE, Bossuyt PM. RESEARCH METHODS AND REPORTING The PRISMA 2020 statement: an updated guideline for reporting systematic reviews Systematic reviews and MetaAnalyses. Published online 2021.

10. Sebastian SK, Kumar VB, Gupta M, Sharma Y. Covid Assossiated Invasive Fungal Sinusitis. Indian J Otolaryngol Head Neck Surg. Published online 2021.

11. John TM, Jacob CN, Kontoyiannis DP. When uncontrolled diabetes mellitus and severe covid-19 converge: The perfect storm for mucormycosis. J Fungi. 2021;7(4).

12. Waizel-Haiat S, Guerrero-Paz JA, Sanchez-Hurtado L, Romero-Gutierrez L. A Case of Fatal RhinoOrbital Mucormycosis Associated With New Onset Diabetic Ketoacidosis and COVID-19. Cureus. 2021;13(2021).

13. Junior ES de M, Santos MEL dos, Baba R. Rare and Fatal Gastrointestional Mucormycosis (Zygomycosis) in a COVID-19 Patient: A Case Report. Clin Endosc. 2020.

14. Singh AK, Singh R. Mucormycosis in COVID-19: A systematic review of cases reported worldwide and in India. Diabetes Metab Syndr Clin Res Rev. Published online 2021;1-7.

15. Prakash H, Chakrabarti A. Global epidemiology of mucormycosis. J Fungi. 2019;5(1).

16. Baldin C, Ibrahim AS. Molecular mechanisms of mucormycosis-The bitter and the sweet. PLoS Pathog. 2017;13(8):1-9.

17. Sen M, Lahane S, Lahane TP. Mucor in a Viral Land: A tale of two pathogens. Indian J Ophthalmol. 2021;69(2).

18. Spellberg B, Jr. JE, Ibrahim A. Novel Perspectives on Mucormycosis: Pathophysiology, Presentation, and Management. Published online 2005:556-69.

19. Raghavendra MV., Kumar Chennamchetty V, Adimulapu S, Patel Kola B, De Padua M, C A. Post-COVID pulmonary mucormycosis- A case report. IP Indian J Immunol Respir Med. 2021;6(1):62-66. 
20. Dronamraju S, Agrawal S, Kumar S. Angioinvasion of Anterior Cerebral Artery by Rhinocerebral Mucormycosis Leading to Intraparenchymal Hemorrhage: A Rare Case Report. Medical Science. 2021;25(111):1088-91.

21. Garg D, Muthu V, Sehgal IS, Bhalla A, Agarwal R. Coronavirus Disease (COVID-19) Associated Mucormycosis (CAM): Case Report and Systematic Review of Literature. Mycopathologia. 2021.

22. Honavar SG, Sen M, Lahane S, Lahane TP, Parekh R. Original Article Mucor in a Viral Land: A Tale of Two Pathogens. Indian J Ophthalmol. 2021;(2).

23. Maini A, Tomar G, Khanna D, Kini Y, Mehta H, Bhagyasree V. Sino-orbital mucormycosis in a COVID-19 patient: A case report. Int J Surg Case Rep. 2021;82:105957.

24. Mishra N, Mutya VSS, Thomas A. A case series of invasive mucormycosis in patients with COVID-19 infection. Int J Otorhinolaryngol Head Neck Surg. 2021;7(5):867.

25. Revannavar SM, P S S, Samaga L, V K V. COVID19 triggering mucormycosis in a susceptible patient: a new phenomenon in the developing world? BMJ Case Rep. 2021;14(4).

26. Saldanha M, Reddy R, Vincent MJ. Title of the Article: Paranasal Mucormycosis in COVID-19 Patient. Indian J Otolaryngol Head Neck Surg. 2021;1-4.

27. Sarkar S, Gokhale T, Choudhury SS, Deb AK. COVID-19 and Orbital Mucormycosis. Indian Journal of Ophthalmology. 2021;69:1002-4.

28. Shirke PD, Chitguppi R. Post-Covid Jaw Osteomyelitis : A Case Series. 2021.

29. Pauli MA, Pereira L de M, Monteiro ML, de Camargo AR, Rabelo GD. Painful palatal lesion in a patient with COVID-19. Oral Surg Oral Med Oral Pathol Oral Radiol. 2021;00(00):1-6.

30. Karimi-Galougahi M, Arastou S, Haseli S. Fulminant mucormycosis complicating coronavirus disease 2019 (COVID-19). Int Forum Allergy Rhinol. 2021;(February):2-3.

31. Ahmadikia K, Hashemi SJ, Khodavaisy S. The double-edged sword of systemic corticosteroid therapy in viral pneumonia: A case report and comparative review of influenza-associated mucormycosis versus COVID-19 associated mucormycosis. Mycoses. 2021;:1-11.

32. Veisi A, Bagheri A, Eshaghi M, Rikhtehgar MH, Rezaei Kanavi M, Farjad R. Rhino-orbital mucormycosis during steroid therapy in COVID-19 patients: A case report. Eur J Ophthalmol. Published online $2021 ; 112067212110094$.
33. Pasero D, Sanna S, Terragni P. A Challenging Complication Following SARS-CoV-2 Infection_a Case of Pulmonary Mucormycosis.2020.

34. Alekseyev K, Didenko L, Chaudhry B. Rhinocerebral Mucormycosis and COVID-19 Pneumonia. 2021;12(3)

35. Kanwar A, Jordan A, Cortes M, Jackson BR. A Fatal Case of Rhizopus azygosporus Pneumonia Following COVID-19. J Fungi. 2021;7(174).

36. Pandian E, Kang J, Cockerham K. The Role of Retrobulbar Liposomal Amphotericin in Orbital Apex Syndrome in a COVID - 19 Positive Diabetic. Journal of Medical Clinical Case Reports. 2021;3:19-21.

37. Dallalzadeh LO, Ozzello DJ, Liu CY, Kikkawa DO, Korn BS. Secondary infection with rhino-orbital cerebral mucormycosis associated with COVID-19. Orbit (London). 2021.

38. Johnson AK, Ghazarian Z, Cendrowski KD, Persichino JG. Pulmonary aspergillosis and mucormycosis in a patient with COVID-19. Med Mycol Case Rep. 2021;32:64-7.

39. Khan N, Gutierrez CG, Martinez DV, Proud KC. A case report of COVID-19 associated pulmonary mucormycosis. Arch Clin Cases. 2020;07(03):4651.

40. Khatri A, Chang K-M, Berlinrut I, Wallach F. Mucormycosis after Coronavirus disease 2019 infection in a heart transplant recipient - Case report and review of literature. J Med Mycol. 2021;31(2):101125.

41. Mekonnen ZK, Ashraf DC, Simko JP, Winn BJ. Acute Invasive Rhino-Orbital Mucormycosis in a Patient With COVID-19-Associated Acute Respiratory Distress Syndrome. 2021;37:2(2021).

42. Placik DA, Taylor WL, Wnuk NM. Bronchopleural fistula development in the setting of novel therapies for acute respiratory distress syndrome in SARSCoV-2 pneumonia. Radiol Case Reports. 2020;15(11):2378-81.

43. Werthman-Ehrenreich A. Mucormycosis with orbital compartment syndrome in a patient with COVID-19. Am J Emerg Med. 2021;42:264.e5-e8.

Cite this article as: Mahato C, Magon N, Prasad S, Tyagi AK. The Mucormycosis surge in COVID-19 pandemic: an analysis of associated risk factors and review of literature of reported cases. Int J Otorhinolaryngol Head Neck Surg 2022;8:298-313. 